\title{
Non-fungible Tokens as an Alternative Investment: Evidence from CryptoPunks
}

${ }^{1}$ Luisa Schaar, ${ }^{2}$ Stylianos Kampakis

${ }^{1}$ Faculty of Law and Management, University of Law, UK

${ }^{2}$ UCL Centre for Blockchain Technologies, University College London, UK

Correspondence: stylianos.kampakis@gmail.com

Received: 15 Nov 2021 Accepted: 17 Dec 2021 Published: 18 January 2022

\begin{abstract}
The Non-fungible Token (NFT) market has experienced extraordinary growth since the beginning of 2021. This has attracted attention from investors who are seeking alternative investments. However, the investment performance of the NFT market has not been investigated yet. This paper explores NFTs as an alternative investment. More specifically, it investigates the NFT collection "CryptoPunks" as an investment option with the focus on evaluating the investment performance, assessing the variables that determine prices, calculating the portfolio diversification potential, and comparing the investment performance to other financial assets. Therefore, a quantitative study with secondary data is conducted using the hedonic regression method. Data on CryptoPunks and other asset types are retrieved from different public domains. The time frame that is observed is 1 June 2018 until 31 May 2021 . The CryptoPunk data set includes 11,864 transactions with information on the collectible and the sale. The results indicate that CryptoPunks would have been the best investment over the past three years with an average monthly return of $34.19 \%$ and a standard deviation of $61.76 \%$. Next to that, the Sharpe ratio indicates a good return-risk trade-off. One other main finding is that the rarity of the attributes and type of the CryptoPunk has a positive effect on prices. Besides that, CryptoPunks has portfolio diversification potential due to relatively low correlation with other asset classes. This paper provides one of the first statistical explorations of NFTs from an economic perspective. The paper also examines the potential of NFTs as an alternative investment asset. The paper concludes that (based on the period studied) NFT collectibles can be a viable investment, with good returns, and a diverse risk profile that is uncorrelated from other benchmark assets, such as art, treasury bills, and major cryptocurrencies.
\end{abstract}

Nothing in this paper can be considered to be financial advice.

Keywords: Non-fungible Tokens, Alternative Investment, Hedonic Regression JEL Classification: G1

\section{Introduction}

NFTs are an investment option that evolved in 2014 from the blockchain space. Digital assets are not new but the opportunity this system provides to allow personal ownership of unique digital property is a ground-breaking development made possible by the existence of the NFT. This market is still relatively new in comparison to the cryptocurrency market and has gained in popularity since the beginning of 2021. The market has shown a growth of $13,118 \%$ to a US $\$ 2$ billion market with " 150,000 users in the first quarter of 2021" [1]. Users have shown interest in various categories of digital assets. That is why NFTs are usually divided into the categories "Collectible", "Game", "DeFi", “Art", "Utility", "Music", "Metaverse", and "Sports". Of these, the category yielding the highest sales volume is "Collectible", while the highest average prices can be observed in the category
"Metaverse" [2]. The most popular NFT platforms are displayed in Table 1. NBA Top Shot is the platform with the highest sales volume, most sales, and the most traders. The platform sells video highlights from the National Basketball Association (NBA). This shows that NFTs cannot only be leveraged as an investment but also used to strategically expand the digital business model of organisations or companies. But despite the success of the NFT market in past months, NFT investment is still new and therefore has opportunities as well as challenges ahead for it.

This data shows that NFTs have high ROI potential and suggests that some investors classify them as new assets since the market shows similar attributes to those of art and cryptocurrency. The main benefit of the art market is that this market has much higher transparency since all activities are publicly available. 
Table 1: Top 10 NFT Projects Sorted by Total Sales Volume up until 1 June 2021 [3]

\begin{tabular}{|l|l|c|c|c|}
\hline \multicolumn{1}{|c|}{$\begin{array}{c}\text { Project/ } \\
\text { Marketplace }\end{array}$} & Category & $\begin{array}{c}\text { Total Sales } \\
\text { Volume (US\$) }\end{array}$ & $\begin{array}{c}\text { Number } \\
\text { of Traders }\end{array}$ & $\begin{array}{c}\text { Total } \\
\text { Sales }\end{array}$ \\
\hline $\begin{array}{l}\text { NBA Top } \\
\text { Shot }\end{array}$ & Sports & $581.59 \mathrm{M}$ & 389,004 & $5,405,678$ \\
\hline CryptoPunks & Collectible & $350.56 \mathrm{M}$ & 3,156 & 13,692 \\
\hline Rarible & All & $108.08 \mathrm{M}$ & 51,348 & 153,381 \\
\hline Sorare & Sports & $77.38 \mathrm{M}$ & 23,752 & 407,115 \\
\hline Meebits & Collectible & $66.62 \mathrm{M}$ & 2,329 & 3,910 \\
\hline Axie Infinity & Metaverse & $62.64 \mathrm{M}$ & 50,984 & 302,962 \\
\hline Hashmarks & Art & $51.18 \mathrm{M}$ & 4,634 & 11,730 \\
\hline Foundation & Art & $42.89 \mathrm{M}$ & 9,521 & 13,855 \\
\hline Decentraland & Metaverse & $42.54 \mathrm{M}$ & 4,493 & 14,295 \\
\hline Waifusion & Collectible & $38.74 \mathrm{M}$ & 2,515 & 37,066 \\
\hline
\end{tabular}

The NFT market is driven by the following attributes:

- Heterogenous asset

- High market transparency

- NFTs are verifiable

- Availability of the market is $24 / 7$

- Low liquidity

- Relatively high transaction cost

- Higher elasticity of supply than the physical art market

- Psychological factors of owning NFTs are different from owning traditional assets

- Price evaluation is not objective

Due to its newness, this market still needs to be explored and analysed. Specifically, pricing is an interesting topic that will help researchers to understand the market from an economic perspective and evaluate the extent to which NFTs are suitable for portfolio diversification and alternative investment. An important factor that is linked to pricing is measuring the financial performance of new assets. This paper will therefore explore NFT collectibles, from the project CryptoPunks, as an investment option; focusing on (i) creating a hedonic index, (ii) assessing the price impact of the hedonic variables, (iii) evaluating risk and return, and (iv) comparing it to other investment assets.

\section{Literature Review}

In general, research on NFTs is very new and therefore it is necessary to consider relevant literature from related fields of research regarding the financial performance of alternative investments. The following markets are reviewed as relevant to this study.

\subsection{NFT Market Pricing}

First, there is a lack of research into pricing and financial performance within the NFT market. Dowling [4] examined the NFT pricing of the metaverse Decentraland. While his study focuses mainly on market efficiency, Dowling's research shows that the average weekly returns on NFT investment between March 2019 and March 2021 were 2.14\% with a standard deviation of $27.54 \%$ [4]. Nevertheless, Dowling [4] concludes that pricing remains inefficient despite a fast increase in value. This is primarily due to the fact that the NFT market is in its early stages. The main shortcoming of this study is that it is based on the assumption that all pieces of virtual land have equal value, which is not the case since they have different characteristics. This inequity in value has a measurable impact on pricing and, accordingly, an approach that is used in the physical real estate market would be more suitable. Another study by Dowling [5] assessed the extent to which NFT pricing is related to or influenced by cryptocurrency prices. The study concludes that there is low volatility transmission, suggesting that NFTs are a lowcorrelation asset class distinct from cryptocurrencies. However, a wavelet coherence analysis indicates that there is co-movement between the two markets. A study by Ante [6] also suggests that the Bitcoin and Ethereum markets impact the development of NFT markets. More specifically, a Bitcoin price shock initiates increased NFT sales. This is important since it helps to assess NFTs' suitability for portfolio diversification.

\subsection{Art and Collectibles Market Pricing}

It is important to look at the art and collectibles market since it also deals in homogenous assets that have characteristics similar to those of the NFT market, e.g., volatility, illiquidity, and irrationality [7]. To measure the financial performance of heterogeneous assets, different indexing methods are required from the ones that are used for homogenous assets.

In considering a range of literature from this market it becomes clear that the two main methods that have been used for this asset type are Repeat-Sales Method (RSM) and Hedonic Regression (HR) [8]. RSM regulates quality by comparing transacted prices for the same asset over time [9]. The theory behind HR, on the other hand, states that an asset's overall price should equal the sum of its utilitygenerating qualities [10].

Burton and Jacobsen [11] purported that most research data within the collectibles market showed a positive financial return, albeit much lower than that of stocks and holding more risk. The real annual returns of collectibles can differ between $-8.7 \%$ and $25.67 \%$ with high standard deviations. Furthermore, a meta-analysis showed that collectibles are negatively correlated to the stock market but their returns in bear markets are low and therefore do not seem to be a good investment option when stock prices fall. An important consideration when researching the art and collectibles market is that perceived psychological benefits are key drivers in buyer decision-making.

As well as its ROI, it is important to look at what drives and determines prices within this market. Koford and Tschoegl 
[12] and Hughes [13] investigated the impact of exclusivity on the price of rare objects and demonstrated that it impacts positively on it. Hughes [13] estimated that the prices of a collectible card game with a rare designation are up to 70-90 times higher than a common card game. Therefore, rarity is an important variable in an analysis of the CryptoPunks collection.

Last, one of the main studies within the art field by Worthington and Higgs [14] showed that the average annual returns of different art markets range from $1.90 \%$ to $4.22 \%$. The researchers concluded that returns on art investment are less than returns on traditional assets, even though the risk is higher; therefore, they argue, art cannot be recommended as a profitable alternative financial investment. A later study by Renneboog and Spaenjers [15] supports Worthington and Higgs's [14] results. It demonstrated that art prices have increased by an average of 3.97\% between 1957 and 2007, the SR being 0.2 . This confirms the hypothesis that art does not have a good risk-adjusted return rate.

The appreciation at the upper end of the market has been higher than the average. Additionally, the hedonic regression analysis shows that "artist reputation, attribution, signs of authenticity, medium, size, topic, and the timing and location of the sale are significantly correlated with price levels" [15]. Interestingly, most sales are completed at the end of spring and fall. Besides timing, the demand for luxury goods and art market confidence are two other driving forces with regard to asset pricing. Even though there are some studies who support art as an alternative investment, the majority of the research suggests that art is not a good option as an alternative investment. The only time art outperforms the S\&P 500 index, according to Zhukova et al. [16], is during periods of negative returns, which seems to make them a safe haven asset in times of crisis.

\section{Data and Methodology}

A quantitative study with secondary data was conducted. This primarily involves the hedonic regression analysis, including variables related to the collectible asset and monthly time dummies. The HR method is chosen because ROIs will be calculated based upon the analysis, with the influence of different variables being assessed. It is based upon those results that the most valuable CryptoPunks will be calculated. Following that calculation, risk and return will be compared to other asset types. Finally, an analysis of the correlation between the returns will give insight into the diversification potential of this NFT type.

\subsection{Research Object}

CryptoPunks was chosen as the main research object since it is one of the NFT marketplaces with the highest trading volume and therefore a suitable and representative research object for this study. Furthermore, CryptoPunks falls under the category "Collectible" which has the highest sales volume among all categories.
According to Larva Labs [17], CryptoPunks is a collection of 10,000 uniquely generated characters with proof of ownership stored on the Ethereum blockchain. All CryptoPunks are $24 \times 24$ pixel art images that were inspired by cyberpunk. The Larva Labs project was also the inspiration for the ERC-721 standard. When the CryptoPunks collection was released, all characters could be claimed for free. Since all of them were claimed very quickly, they can now be traded via Larva Labs or OpenSeas. On both those marketplaces, it is possible to offer, bid on, and purchase punks.

The characters are based on a set of CryptoPunks types and attributes. Figure 1 shows the prevalence of each CryptoPunk type. More than half of the CryptoPunks are "Male." There are nine "Alien" CryptoPunks. Furthermore, there is a total of 87 attributes (see Appendix 1). Some attributes are represented more often than others. The most common attribute is the "Earring" which is seen in 2,459 CryptoPunks. In contrast to that, only 44 CryptoPunks have a "Beanie" attribute. On average the 87 attributes are represented 316.54 times with a standard deviation of 288.15. More information on prevalence is provided on Table 10 in the appendix.

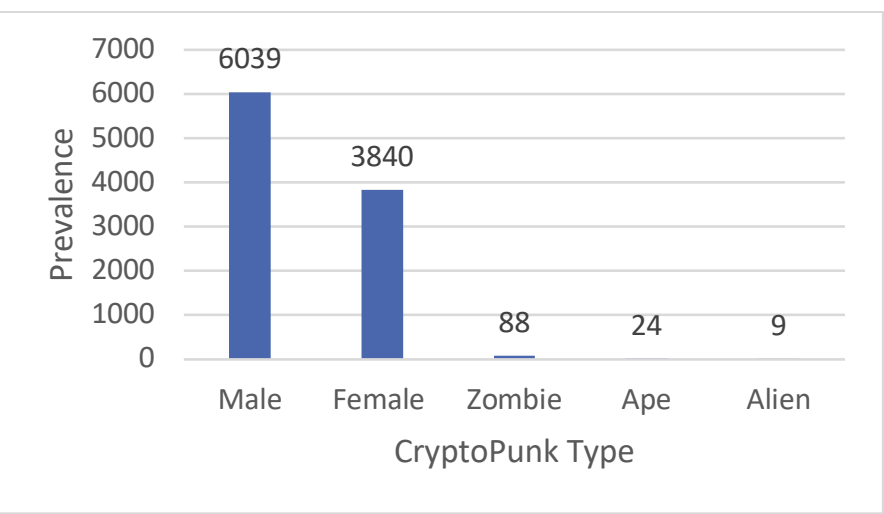

Figure 1: Prevalence of CryptoPunk Types

The number of attributes that a CryptoPunk has varies between zero and seven (see Figure 2). Only one CryptoPunk has seven attributes, making it the rarest CryptoPunk in terms of the number of assets it represents. A total of 4,501 CryptoPunks have three attributes making this attribute count the most common, making up almost half of all existing CryptoPunks. Shortly behind that is the prevalence of CryptoPunks with two attributes, totalling 3,560.

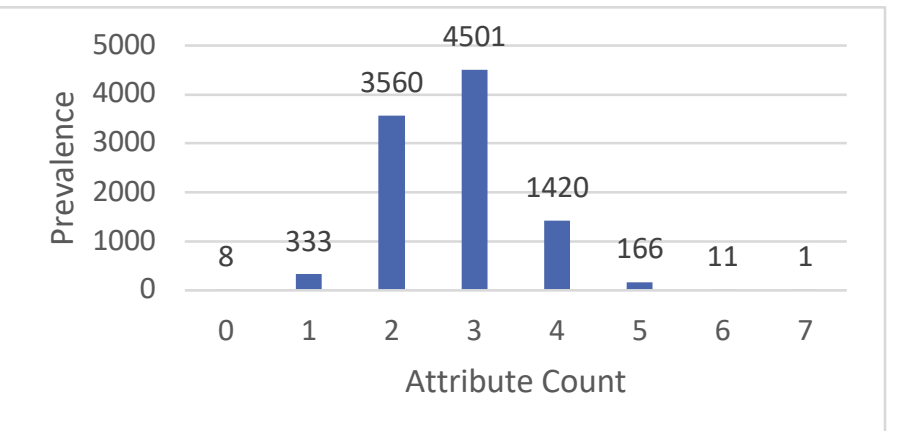

Figure 2: Prevalence of Number of Attributes 


\subsection{Data}

Data on CryptoPunks and other asset types are retrieved from various public domains. The time frame observed for data retrieval is 1 June 2018 to 31 May 2021. Year One in the analysis will therefore be the period from June 2018 to May 2019. The same model will be applied to the subsequent two years.

\subsubsection{CryptoPunks}

Historical trading data from all CryptoPunks sales transactions across the three years is retrieved from cryptoslam.io. All sales can be classified as secondary market sales since all CryptoPunks were given away for free for the primary sale before the observed period.

This data set comprises 11,864 transactions, each with information on the Seller and Buyer Addresses, CyrptoPunk ID, CryptoPunk type, Ethereum price, USD price, and CryptoPunk attributes. Cryposlam.io does not provide the exact transaction date in its transaction overview. Therefore, dates were entered manually by matching the transaction to the date listed in its corresponding "transaction data overview" on nonfungible.com. The prices that are listed are exclusive of the transaction cost. Additionally, this study will not include bidding prices.

Sales were conducted on 790 of possible 1,096 days. Most sales (320) were completed on 28 September 2020. Generally, the sales were fairly constant with occasional peaks. The sales hit the highest point in September 2020 but receded after that. Then they picked up again at the beginning of 2021. In total there were 923 sales in Year One, 1,773 in Year Two, and 9,168 in Year Three.

A total of 4,759 CryptoPunks were sold at least once during the three observed years. More specifically the number of sales a single CryptoPunk generated varied between 1 and 15 (see Figure 3). The CryptoPunks with the most resales are the CryptoPunks "9117" and "2937", both with 15 resales. The majority of CryptoPunks $(1,866)$ were sold just once during the observed time frame.

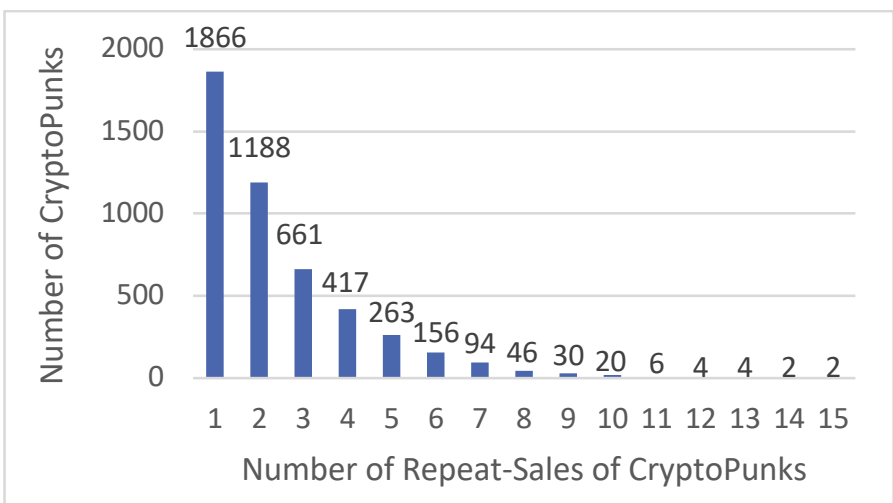

Figure 3: Repeat-Sales of CryptoPunks
The most expensive transactions in the time period observed are the sales of CryptoPunk "7804" and " 3100 " for 4,200 ETH or US $\$ 7,676,397$ on 11 March 2021. The average pricing varies significantly depending on the year observed (see Table 2). The average price increased $217 \%$ from the first to the second year and $13,353 \%$ from the second to the third year.

Table 2: Average Annual Sale Price and Sales Volume

\begin{tabular}{|c|c|c|c|}
\hline & Year 1 & Year 2 & Year 3 \\
\hline Sale Price Mean & US\$88.32 & US $\$ 279.83$ & US\$37,645.82 \\
\hline Standard Deviation & 224.40 & 927.54 & 128930.42 \\
\hline Total Sales Volume & US\$81,521.05 & US\$496,129.90 & US\$345,136,847.91 \\
\hline
\end{tabular}

\subsubsection{Other Assets}

To be able to compare the returns and risks associated with NFTs, corresponding data from other assets need to be retrieved from different online sources. The US and World Equity market data is collected from MSCI, the 10-Year US Government Bond Index is collected from investing.com, as is the Bitcoin and Ethereum Index, while the Real Estate Investment Trusts Index (NAREIT) is gathered from reit.com. Art market data could not be retrieved due to limited accessibility.

Furthermore, the monthly US T-Bill Risk-Free Rate is used as the risk-free rate retrieved from the Federal Reserve Economic Data database. The T-Bill is perceived as nearly risk-free since it is fully backed by the government. Hence it is often used by researchers and investors as the risk-free rate.

\subsection{Method}

\subsubsection{Hedonic Regression of CryptoPunks}

To index CryptoPunks, the hedonic regression method is chosen over the repeat-sales method since Ginsburgh et al. [8] demonstrated that HR outperforms RSR when the sample size is small. Furthermore, most CryptoPunks sales in the time period observed are not repeat-sales, making HR more suitable. One major benefit of this method is that it takes into account all information related to the transaction. This model regresses natural log returns to different time dummies while taking different hedonic characteristics into account.

The mathematical expression of the HR model for CryptoPunks is:

$$
\begin{aligned}
\ln \llbracket P_{-} c t \rrbracket & =\alpha+\sum_{-}(v \\
& =1)^{\wedge} V \text { U } \\
& =1)^{\wedge} T \beta_{-} v X_{-} v c t \rrbracket+\sum_{-}(t \\
&
\end{aligned}
$$

The price of the CryptoPunk $c$ at the time $t$ is $P_{-} c t$. $X_{-} v c t$ represents the value of the variable $v$ of the CryptoPunk $c$ at the time $t$. The coefficient $\beta \_v$ reflects the influence of 
variable $v$. The time dummy variable $D_{-} c t$ equals 1 if the CryptoPunk $c$ is sold in period $t$. A monthly time period is chosen for the index and returns because there are too many days without sales to have reliable daily or weekly data.

The coefficient $\gamma_{-} t$ is used to create the price index $I_{-} t$ using antilogs. In the time period $t$ the value of the hedonic index is:

$$
I_{-} t=\exp \left(\gamma_{-} t\right) " x " 100
$$

The estimated return in the time period $t$ can be calculated by setting the time dummy coefficient to 0 for the first time period. The return of the period $t$ can then be calculated based on the following:

$$
r_{-} t=\frac{I_{t}}{I_{t-1}}-1
$$

The price impact $P I_{v}$ of the hedonic variables is calculated using the coefficient $\beta_{v}$ of each variable. Therefore, the price impact of variable $v$ is:

$$
P I_{v}=\exp \left(\beta_{v}\right)-1
$$

Based on this the most valuable CryptoPunk $M V P_{c}$ can be estimated in order to evaluate which are the most valuable CryptoPunks.

$$
\begin{aligned}
M V P_{c}=P I_{v_{p t}} & +P I_{v_{\text {noa }}}+\left(\frac{1}{\text { Number of Attributes }}\right. \\
& \left.* \sum_{a=1}^{a} P I_{v_{a}}\right)
\end{aligned}
$$

The most valuable CryptoPunks are calculated by adding the price impact of the CryptoPunk type $P I_{v_{p t}}$ to the price impact of the number of attributes $P I_{v_{n o a}}$ which the CryptoPunk exhibits and the average price impact of the CryptoPunk's attributes $P I_{v_{a}}$. The average of the CryptoPunk's attributes $P I_{v_{a}}$ is taken to not duplicate the impact of $P I_{v_{n o a}}$. If the CryptoPunk has zero attributes, then the following applies:

$$
M V P_{c}=P I_{v_{p t}}+P I_{v_{\text {noa }}}
$$

\subsubsection{Hedonic Variables}

HR analysis includes different variables relating to the collectible. In terms of collectible-related characteristics, all differentiating variables are included. With regard to sales characteristics, seasonality is a relevant variable. But it will not be included in this study since the time dummies are monthly periods. Including general monthly variables and monthly time dummies would only lead to distorted regression results and therefore they are excluded. However, the monthly time dummies will be used to check for seasonality. The point of sale is also excluded since more than $99 \%$ of all sales were conducted through Larva Lab's marketplace. The descriptive statistic is presented in Table 3. The variables are all dummy variables and therefore equal 1 if the variable is exhibited in the CryptoPunk and 0 if it is not.

CryptoPunk. Type. The five different types of CryptoPunks have different prevalences and therefore some are rarer than others. As posited in the literature review, rarity has an effect on the pricing of physical collectibles. The sales share of each CryptoPunk type is related to the prevalence of each type. More than half of the total sales recorded during the three years were "Male" CryptoPunks, while "Alien" CryptoPunks were sold only three times.

Attributes. Next to the CryptoPunk type, the 87 attributes determine the visual appearance of the CryptoPunk. Rarity has an impact here too. CryptoPunks with the "Earring" attribute accounted for $26.13 \%$ of the sales, which is the most common of the 87. Conversely, the "Pilot Helmet" attribute is the least exhibited, only featuring in 26 of total sales.

Number of Attributes. The sales breakdown for this variable would appear from the data to be linked to the prevalence of the number of attributes in the set of CryptoPunks. Almost half of the CryptoPunks that were sold had three attributes. In contrast, only two transactions of CryptoPunks with seven attributes were observed.

Table 3: Descriptive Statistics of the Hedonic Variables of CryptoPunks with $N=11,864$

\begin{tabular}{|l|c|c|c|c|}
\hline & Mean & SD & $\mathbf{0}$ & $\mathbf{1}$ \\
\hline CryptoPunk Type & & & & \\
\hline Male & 0.6931 & 0.4612 & 3641 & 8223 \\
\hline Female & 0.3003 & 0.4584 & 8301 & 3563 \\
\hline Zombie & 0.0052 & 0.0721 & 11802 & 62 \\
\hline Ape & 0.0011 & 0.0331 & 11851 & 13 \\
\hline Alien & 0.0003 & 0.0159 & 11861 & 3 \\
\hline Number of Attributes & & & & \\
\hline Zero Attributes & 0.0005 & 0.0225 & 11858 & 6 \\
\hline One Attribute & 0.0115 & 0.1068 & 11727 & 137 \\
\hline Two Attributes & 0.3449 & 0.4753 & 7772 & 4092 \\
\hline Three Attributes & 0.4898 & 0.4999 & 6053 & 5811 \\
\hline Four Attributes & 0.1386 & 0.3455 & 10220 & 1644 \\
\hline Five Attributes & 0.0136 & 0.1157 & 11703 & 161 \\
\hline Six Attributes & 0.0009 & 0.0304 & 11853 & 11 \\
\hline Seven Attributes & 0.0002 & 0.0130 & 11862 & 2 \\
\hline Attributes & & & & \\
\hline Beanie & 0.0058 & 0.0760 & 11795 & 69 \\
\hline Choker & 0.0038 & 0.0615 & 11819 & 45 \\
\hline Pilot Helmet & 0.0023 & 0.0477 & 11837 & 27 \\
\hline Tiara & 0.0024 & 0.0485 & 11836 & 28 \\
\hline Orange Side & 0.0040 & 0.0628 & 11817 & 47 \\
\hline Buck Teeth & 0.0048 & 0.0691 & 11807 & 57 \\
\hline Welding Goggles & 0.0051 & 0.0715 & 11803 & 61 \\
\hline Pigtails & 0.0063 & 0.0793 & 11789 & 75 \\
\hline Pink with Hat & 0.0070 & 0.0833 & 11781 & 83 \\
\hline Top Hat & 0.0083 & 0.0910 & 11765 & 99 \\
\hline Spots & 0.0126 & 0.1114 & 11715 & 149 \\
\hline
\end{tabular}




\begin{tabular}{|c|c|c|c|c|c|c|c|c|c|}
\hline & Mean & SD & 0 & 1 & & Mean & SD & $\mathbf{0}$ & 1 \\
\hline Rosy Cheeks & 0.0129 & 0.1128 & 11711 & 153 & Shadow Beard & 0.0596 & 0.2367 & 11157 & 707 \\
\hline Blonde Short & 0.0078 & 0.0877 & 11772 & 92 & Regular Shades & 0.0562 & 0.2303 & 11197 & 667 \\
\hline Wild White Hair & 0.0089 & 0.0937 & 11759 & 105 & Big Shades & 0.0535 & 0.2251 & 11229 & 635 \\
\hline Cowboy Hat & 0.0113 & 0.1057 & 11730 & 134 & Horned Rim Glasses & 0.0538 & 0.2256 & 11226 & 638 \\
\hline Straight Hair Blonde & 0.0107 & 0.1029 & 11737 & 127 & Nerd Glasses & 0.0577 & 0.2332 & 11179 & 685 \\
\hline Wild Blonde & 0.0058 & 0.0760 & 11795 & 69 & Black Lipstick & 0.0541 & 0.2262 & 11222 & 642 \\
\hline Big Beard & 0.0122 & 0.1099 & 11719 & 145 & Mole & 0.0802 & 0.2717 & 10912 & 952 \\
\hline Red Mohawk & 0.0095 & 0.0971 & 11751 & 113 & Purple Lipstick & 0.0498 & 0.2176 & 11273 & 591 \\
\hline Vampire Hair & 0.0239 & 0.1529 & 11580 & 284 & Hot Lipstick & 0.0545 & 0.2269 & 11218 & 646 \\
\hline Blonde Bob & 0.0079 & 0.0887 & 11770 & 94 & Cigarette & 0.0936 & 0.2913 & 10753 & 1111 \\
\hline Half Shaved & 0.0114 & 0.1061 & 11729 & 135 & Earring & 0.2613 & 0.4393 & 8764 & 3100 \\
\hline
\end{tabular}

Despite the month of sale being excluded as a hedonic variable, the descriptive statistics of the time dummy variables reveal that most CryptoPunk sales happened in February and September closely followed by March, April, and May (see Table 4). Seasonality often has an effect on sales and pricing. This has already been mentioned with regard to the art market, where sales have been clustered in certain time frames.

Table 4: Descriptive Statistics of the Month of Sale of CryptoPunks with $N=11,864$

\begin{tabular}{|l|c|c|c|c|}
\hline Month of Sale & Mean & SD & $\mathbf{0}$ & $\mathbf{1}$ \\
\hline January & 0.0801 & 0.2714 & 10914 & 950 \\
\hline February & 0.1870 & 0.3899 & 9645 & 2219 \\
\hline March & 0.1309 & 0.3373 & 10311 & 1553 \\
\hline April & 0.1184 & 0.3231 & 10459 & 1405 \\
\hline May & 0.1290 & 0.3352 & 10334 & 1530 \\
\hline June & 0.0298 & 0.1699 & 11511 & 353 \\
\hline July & 0.0125 & 0.1110 & 11716 & 148 \\
\hline August & 0.0171 & 0.1297 & 11661 & 203 \\
\hline September & 0.1909 & 0.3930 & 9599 & 2265 \\
\hline October & 0.0485 & 0.2147 & 11289 & 575 \\
\hline November & 0.0201 & 0.1402 & 11626 & 238 \\
\hline December & 0.0358 & 0.1858 & 11439 & 425 \\
\hline
\end{tabular}

\subsubsection{Comparison of Investment Performances and Correlation of Assets}

In order to assess the performance, the return and risk rates of the different assets are calculated and evaluated. The return rate $r_{t}$ will be calculated in order to compare the returns. In evaluating risk, the Sharpe ratio (SR) is used. Finally, the correlation of the returns is assessed in order to get an understanding of whether NFTs are suitable for portfolio diversification.

\section{Hedonic Regression}

The data set of the 11,864 observed transactions has complete information on all variables that are listed in the previous section. Three of the hedonic variables and a time dummy variable could not be defined because of singularities. The $\mathrm{R}^{2}$ shows that $97.18 \%$ of the variance of $\ln P_{c t}$ is explained by the independent variables as specified. The $p$-value is $<0.001$ for 
the overall regression analysis and therefore highly significant. Generally, the regression analysis shows very good fit which is supported by the actual vs. fitted and fitted vs. predicted plots (see Appendix 2 - figures 5 and 6).

Table 5 shows the coefficient, standard deviation, significance level, and calculated price impact of each hedonic variable. The analysis shows that CryptoPunks are on average priced $307.10 \%$ higher if they belong to the CryptoPunk type "Alien." All other CryptoPunk types are priced lower on average. The same appears true for the number of attributes. CryptoPunks with zero attributes are, on average, priced $329.56 \%$ higher while the price drops more than $30 \%$ for CryptoPunks with attributes. The specific attribute a CryptoPunk has also influences price. Most attributes have a positive effect on pricing. The "Beanie" attribute stands out since CryptoPunks with this attribute have on average $563.92 \%$ higher prices. Besides that, the attributes "Pilot Helmet," "Orange Side," "Choker," "Welding Goggles," "Buck Teeth," "Pink with Hat," "Pigtails," and "Hoodie" increase the price by an average of over $100 \%$. Unfortunately, the coefficient of the most common attribute "Earring" could not be calculated because of singularities.

Generally, it can be observed that rarity plays a role when it comes to CryptoPunk pricing. This can be deduced from the data showing that 9 of the 10 rarest attributes are also within the top 10 attributes having the highest price impact. Additionally, the type "Alien" belongs to one of the rarest types too. The same pattern is seen in impact of the number of attributes. CryptoPunks with seven and zero attributes are very rare. Although the impact of seven attributes could not be calculated, data shows that having zero attributes impacts the most highly on a CryptoPunk's price.

This study's findings regarding the price impact of certain hedonic variables can only be used for the CryptoPunk collection. This accords with the findings of Koford and Tschoegl [12] and Hughes [13] who found that rarity has a positive effect on pricing in the case of physical collectibles.

Table 5: Hedonic Variables Regression Results (Signif. codes: 0 “***” 0.001 “**” 0.01 “*” 0.05 “.” 0.1 “" 1)

\begin{tabular}{|l|c|c|c|c|}
\hline Variables & $\begin{array}{c}\text { Coefficient } \\
\boldsymbol{\beta}_{\boldsymbol{v}}\end{array}$ & SD & Significance & $\begin{array}{c}\text { Price } \\
\text { impact } \\
\boldsymbol{P I}_{\boldsymbol{v}} \text { in \% }\end{array}$ \\
\hline $\begin{array}{l}\text { CryptoPunk } \\
\text { Type }\end{array}$ & & & & \\
\hline Alien & 1.403881 & 0.281659 & $* * *$ & $307.10 \%$ \\
\hline Zombie & -0.979351 & 0.136118 & $* * *$ & $-62.44 \%$ \\
\hline Female & -3.18772 & 0.125224 & $* * *$ & $-95.87 \%$ \\
\hline Male & -3.26573 & 0.124781 & $* * *$ & $-96.18 \%$ \\
\hline Ape & $\mathrm{NA}$ & $\mathrm{NA}$ & $\mathrm{NA}$ & $\mathrm{NA}$ \\
\hline $\begin{array}{l}\text { Number of } \\
\text { Attributes }\end{array}$ & & & & \\
\hline Zero Attributes & 1.457601 & 0.375266 & $* * *$ & $329.56 \%$ \\
\hline Six Attributes & -0.413039 & 0.34953 & & $-33.84 \%$ \\
\hline One Attribute & -1.6052 & 0.329017 & $* * *$ & $-79.92 \%$ \\
\hline Five Attributes & -1.881472 & 0.3246 & $* * *$ & $-84.76 \%$ \\
\hline
\end{tabular}

\begin{tabular}{|c|c|c|c|c|}
\hline Variables & $\begin{array}{c}\text { Coefficient } \\
\boldsymbol{\beta}_{v}\end{array}$ & SD & Significance & $\begin{array}{c}\text { Price } \\
\text { impact } \\
P I_{v} \text { in \% }\end{array}$ \\
\hline Two Attributes & -2.331351 & 0.324847 & $* * *$ & $-90.28 \%$ \\
\hline Four Attributes & -2.350086 & 0.323409 & *** & $-90.46 \%$ \\
\hline Three Attributes & -2.364675 & 0.324001 & **** & $-90.60 \%$ \\
\hline Seven Attributes & NA & NA & NA & NA \\
\hline \multicolumn{5}{|l|}{ Attributes } \\
\hline Beanie & 1.892993 & 0.063087 & $* * *$ & $563.92 \%$ \\
\hline Tiara & 1.558338 & 0.090508 & $* * *$ & $375.09 \%$ \\
\hline Pilot Helmet & 1.531511 & 0.092246 & $* * *$ & $362.52 \%$ \\
\hline Orange Side & 1.252443 & 0.073339 & $* * *$ & $249.89 \%$ \\
\hline Choker & 0.967288 & 0.067152 & $* * *$ & $163.08 \%$ \\
\hline Welding Goggles & 0.925417 & 0.058118 & $* * *$ & $152.29 \%$ \\
\hline Buck Teeth & 0.86351 & 0.060478 & $* * *$ & $137.15 \%$ \\
\hline Pink with Hat & 0.799198 & 0.05987 & *** & $122.38 \%$ \\
\hline Pigtails & 0.783312 & 0.061867 & $* * *$ & $118.87 \%$ \\
\hline Hoodie & 0.696302 & 0.045317 & $* * *$ & $100.63 \%$ \\
\hline Wild Blonde & 0.656021 & 0.063774 & $* * *$ & $92.71 \%$ \\
\hline Top Hat & 0.655967 & 0.056337 & $* * *$ & $92.70 \%$ \\
\hline 3D Glasses & 0.594291 & 0.031657 & **** & $81.17 \%$ \\
\hline Wild White Hair & 0.474065 & 0.055683 & $* * *$ & $60.65 \%$ \\
\hline Big Beard & 0.466777 & 0.038891 & $* * *$ & $59.48 \%$ \\
\hline Gold Chain & 0.462519 & 0.03968 & $* * *$ & $58.81 \%$ \\
\hline Medical Mask & 0.45622 & 0.034913 & **** & $57.81 \%$ \\
\hline Cowboy Hat & 0.413984 & 0.051086 & **** & $51.28 \%$ \\
\hline Blonde Bob & 0.403481 & 0.057649 & $* * *$ & $49.70 \%$ \\
\hline $\begin{array}{l}\text { Straight Hair } \\
\text { Blonde }\end{array}$ & 0.399676 & 0.052702 & $* * *$ & $49.13 \%$ \\
\hline VR & 0.35474 & 0.026392 & $* * *$ & $42.58 \%$ \\
\hline Rosy Cheeks & 0.287597 & 0.037385 & $* * *$ & $33.32 \%$ \\
\hline $\begin{array}{l}\text { Clown Hair } \\
\text { Green }\end{array}$ & 0.285134 & 0.048601 & *** & $32.99 \%$ \\
\hline Tassle Hat & 0.259975 & 0.052336 & $* * *$ & $29.69 \%$ \\
\hline Smile & 0.205879 & 0.031021 & $* * *$ & $22.86 \%$ \\
\hline Blonde Short & 0.202156 & 0.05835 & $* * *$ & $22.40 \%$ \\
\hline Big Shades & 0.193163 & 0.020822 & $* * *$ & $21.31 \%$ \\
\hline Luxurious Beard & 0.192994 & 0.031449 & **** & $21.29 \%$ \\
\hline Spots & 0.185761 & 0.037871 & $* * *$ & $20.41 \%$ \\
\hline Red Mohawk & 0.183916 & 0.046209 & $* * *$ & $20.19 \%$ \\
\hline Purple Hair & 0.17873 & 0.047586 & $* * *$ & $19.57 \%$ \\
\hline Clown Nose & 0.171243 & 0.030182 & $* * *$ & $18.68 \%$ \\
\hline Silver Chain & 0.156089 & 0.029679 & **** & $16.89 \%$ \\
\hline Police Cap & 0.15109 & 0.038733 & $* * *$ & $16.31 \%$ \\
\hline Blue Eye Shadow & 0.150178 & 0.029928 & $* * *$ & $16.20 \%$ \\
\hline Pipe & 0.129869 & 0.025815 & $* * *$ & $13.87 \%$ \\
\hline Vape & 0.109658 & 0.030802 & **** & $11.59 \%$ \\
\hline Half Shaved & 0.102164 & 0.051757 & $*$ & $10.76 \%$ \\
\hline Nerd Glasses & 0.092235 & 0.020369 & $* * *$ & $9.66 \%$ \\
\hline Classic Shades & 0.089568 & 0.020136 & $* * *$ & $9.37 \%$ \\
\hline $\begin{array}{l}\text { Green Eye } \\
\text { Shadow }\end{array}$ & 0.073256 & 0.032783 & * & $7.60 \%$ \\
\hline Crazy Hair & 0.0716 & 0.041269 & . & $7.42 \%$ \\
\hline Cigarette & 0.067177 & 0.016705 & $* * *$ & $6.95 \%$ \\
\hline Purple Lipstick & 0.058551 & 0.023351 & * & $6.03 \%$ \\
\hline Straight Hair & 0.053493 & 0.050298 & & $5.49 \%$ \\
\hline Clown Eyes Blue & 0.052906 & 0.024333 & $*$ & $5.43 \%$ \\
\hline Regular Shades & 0.048207 & 0.020254 & * & $4.94 \%$ \\
\hline Eye Mask & 0.047955 & 0.025687 & . & $4.91 \%$ \\
\hline $\begin{array}{l}\text { Horned Rim } \\
\text { Glasses }\end{array}$ & 0.043736 & 0.020699 & $*$ & $4.47 \%$ \\
\hline Small Shades & 0.043611 & 0.021675 & $*$ & $4.46 \%$ \\
\hline Vampire Hair & 0.043547 & 0.04278 & & $4.45 \%$ \\
\hline $\begin{array}{l}\text { Purple Eye } \\
\text { Shadow }\end{array}$ & 0.041206 & 0.028767 & & $4.21 \%$ \\
\hline Eye Patch & 0.04074 & 0.020871 & 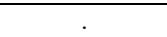 & $4.16 \%$ \\
\hline $\begin{array}{l}\text { Straight Hair } \\
\text { Dark }\end{array}$ & 0.03957 & 0.049933 & & $4.04 \%$ \\
\hline Cap Forward & 0.036269 & 0.032242 & & $3.69 \%$ \\
\hline $\begin{array}{l}\text { Normal Beard } \\
\text { Black }\end{array}$ & 0.025393 & 0.027857 & & $2.57 \%$ \\
\hline Fedora & 0.022607 & 0.043143 & & $2.29 \%$ \\
\hline Frown & 0.022101 & 0.024602 & & $2.23 \%$ \\
\hline Hot Lipstick & 0.021415 & 0.022641 & & $2.16 \%$ \\
\hline
\end{tabular}




\begin{tabular}{|l|c|c|c|c|}
\hline Variables & $\begin{array}{c}\text { Coefficient } \\
\boldsymbol{\beta}_{\boldsymbol{v}}\end{array}$ & SD & Significance & $\begin{array}{c}\text { Price } \\
\text { impact } \\
\boldsymbol{P I}_{\boldsymbol{v}} \text { in } \%\end{array}$ \\
\hline Shadow Beard & 0.021083 & 0.020546 & & $2.13 \%$ \\
\hline Dark Hair & 0.015447 & 0.048713 & & $1.56 \%$ \\
\hline Goat & 0.007871 & 0.024173 & & $0.79 \%$ \\
\hline Mohawk Thin & 0.005869 & 0.025899 & & $0.59 \%$ \\
\hline Handlebars & 0.005391 & 0.02491 & & $0.54 \%$ \\
\hline Moustache & 0.003744 & 0.024163 & & $0.38 \%$ \\
\hline Chinstrap & -0.003858 & 0.024062 & & $-0.39 \%$ \\
\hline Front Beard & -0.007551 & 0.025611 & & $-0.75 \%$ \\
\hline Normal Beard & -0.012703 & 0.024316 & & $-1.26 \%$ \\
\hline Front Beard & -0.015006 & 0.023931 & & $-1.49 \%$ \\
Dark & & & & \\
\hline Clown Eyes & -0.015894 & 0.023886 & & $-1.58 \%$ \\
Green & & & & $-1.89 \%$ \\
\hline Mohawk Dark & -0.019095 & 0.026795 & & $-1.97 \%$ \\
\hline Black Lipstick & -0.019939 & 0.022715 & & $-2.29 \%$ \\
\hline Mutton Chops & -0.023133 & 0.023287 & & $-3.08 \%$ \\
\hline Mole & -0.031284 & 0.017641 & & $-3.35 \%$ \\
\hline Cap & -0.034099 & 0.040557 & & $-4.79 \%$ \\
\hline Messy Hair & -0.049069 & 0.039029 & & $-4.94 \%$ \\
\hline Wild Hair & -0.050631 & 0.039528 & & $-5.54 \%$ \\
\hline Shaved Head & -0.057036 & 0.039351 & & $-7.15 \%$ \\
\hline Peak Spike & -0.074237 & 0.041745 & & $-7.93 \%$ \\
\hline Mohawk & -0.082596 & 0.039002 & $*$ & $-8.62 \%$ \\
\hline Headband & -0.090165 & 0.039518 & $*$ & $-8.89 \%$ \\
\hline Knitted Cap & -0.09312 & 0.028428 & $* *$ & $-9.02 \%$ \\
\hline Bandana & -0.094574 & 0.037951 & $*$ & $-9.21 \%$ \\
\hline Do-rag & -0.096638 & 0.039451 & $*$ & $-11.42 \%$ \\
\hline Frumpy Hair & -0.097809 & 0.03877 & $*$ & $\mathrm{NA}$ \\
\hline Stringy Hair & -0.121214 & 0.037733 & $* *$ & \\
\hline Earring & $\mathrm{NA}$ & $\mathrm{NA}$ & $\mathrm{NA}$ & \\
\hline & & & & \\
\hline
\end{tabular}

Based on the coefficients of the time dummy variables the CryptoPunk index was calculated. The results are presented in Table 6 where the prices are standardised to June 2018 levels. The index is highly significant since most coefficients show $p$ values below 0.001 . The index clearly shows a heavy increase from the end of 2020. It reaches its highest point of 161226.61 at the end of the observed period, in May 2021. On the other hand, the index dropped to its lowest point of 63.15 in December 2018.

Generally, strong variations in return rates can be observed. The highest return rate can be identified at $285.92 \%$ between January and February 2021, while the highest negative return occurred between February and March 2020 at $-44.14 \%$. The average monthly return is $34.19 \%$ with a standard deviation of $61.76 \%$. Dowling studied the pricing of a different NFT category (see [4]) and a comparison of studies shows that the behaviour of the returns of Decentraland and CryptoPunks is fairly similar. The actual Decentraland returns are, however, less than CryptoPunks', since the average monthly return of the former category is around $9 \%$.

Another remarkable observation is that the performance of CryptoPunks basically exploded during the global pandemic, despite a global recession. This might reflect that investments in art and cryptocurrency seem a safe haven in times of financial crises $[18,16]$. Logic thereby follows that diversifying portfolios with such assets limits risk during uncertain times. Unfortunately, the NFT market is currently too new to make a sound examination on this topic.
Table 6: CryptoPunk Index and Returns (Signif. codes: 0 “***» 0.001 “**” 0.01 “*” 0.05 “.” 0.1 “" 1)

\begin{tabular}{|c|c|c|c|c|c|}
\hline Month & $\begin{array}{c}\text { Coefficient } \\
\gamma_{t}\end{array}$ & SD & $\begin{array}{l}\text { Signifi } \\
\text { cance }\end{array}$ & Index $I_{t}$ & $\begin{array}{l}\text { Return } \\
r_{t} \text { in } \%\end{array}$ \\
\hline Jun 18 & NA & $\mathrm{NA}$ & NA & 100 & \\
\hline Jul 18 & 0.032459 & 0.122024 & & 103.30 & $3.30 \%$ \\
\hline Aug 18 & -0.064528 & 0.080106 & & 93.75 & $-9.24 \%$ \\
\hline Sep 18 & -0.213795 & 0.082091 & $* *$ & 80.75 & $-13.87 \%$ \\
\hline Oct 18 & -0.176217 & 0.067063 & $* *$ & 83.84 & $3.83 \%$ \\
\hline Nov 18 & -0.458275 & 0.068871 & $* * *$ & 63.24 & $-24.58 \%$ \\
\hline Dec 18 & -0.459655 & 0.060253 & $* * *$ & 63.15 & $-0.14 \%$ \\
\hline Jan 19 & -0.007222 & 0.066795 & & 99.28 & $57.21 \%$ \\
\hline Feb 19 & 0.113468 & 0.078309 & & 112.02 & $12.83 \%$ \\
\hline Mar 19 & 0.344017 & 0.068457 & $* * *$ & 141.06 & $25.93 \%$ \\
\hline Apr 19 & 0.466177 & 0.066497 & $* * *$ & 159.39 & $12.99 \%$ \\
\hline May 19 & 0.728302 & 0.055673 & $* * *$ & 207.16 & $29.97 \%$ \\
\hline Jun 19 & 0.996758 & 0.057316 & $* * *$ & 270.95 & $30.79 \%$ \\
\hline Jul 19 & 0.564781 & 0.074765 & $* * *$ & 175.91 & $-35.08 \%$ \\
\hline Aug 19 & 0.54873 & 0.074905 & $* * *$ & 173.11 & $-1.59 \%$ \\
\hline Sep 19 & 0.097304 & 0.057792 & . & 110.22 & $-36.33 \%$ \\
\hline Oct 19 & 0.364021 & 0.098988 & $* * *$ & 143.91 & $30.57 \%$ \\
\hline Nov 19 & 0.102881 & 0.067063 & & 110.84 & $-22.98 \%$ \\
\hline Dec 19 & 0.21907 & 0.063273 & $* * *$ & 124.49 & $12.32 \%$ \\
\hline Jan 20 & 0.850521 & 0.050397 & *** & 234.09 & $88.03 \%$ \\
\hline Feb 20 & 1.429165 & 0.067135 & $* * *$ & 417.52 & $78.36 \%$ \\
\hline Mar 20 & 0.846884 & 0.081427 & $* * *$ & 233.24 & $-44.14 \%$ \\
\hline Apr 20 & 1.162363 & 0.063677 & $* * *$ & 319.75 & $37.09 \%$ \\
\hline May 20 & 1.784155 & 0.048357 & $* * *$ & 595.45 & $86.23 \%$ \\
\hline Jun 20 & 2.020327 & 0.062477 & $* * *$ & 754.08 & $26.64 \%$ \\
\hline Jul 20 & 2.004889 & 0.066848 & $* * *$ & 742.53 & $-1.53 \%$ \\
\hline Aug 20 & 2.22519 & 0.062185 & $* * *$ & 925.52 & $24.65 \%$ \\
\hline Sep 20 & 3.217701 & 0.045925 & $* * *$ & 2497.06 & $169.80 \%$ \\
\hline Oct 20 & 3.700141 & 0.049086 & $* * *$ & 4045.30 & $62.00 \%$ \\
\hline Nov 20 & 3.755422 & 0.064714 & $* * *$ & 4275.23 & $5.68 \%$ \\
\hline Dec 21 & 4.216632 & 0.054256 & $* * *$ & 6780.47 & $58.60 \%$ \\
\hline Jan 21 & 4.983607 & 0.048944 & $* * *$ & 14600.01 & $115.32 \%$ \\
\hline Feb 21 & 6.334063 & 0.045827 & $* * *$ & 56344.12 & $285.92 \%$ \\
\hline Mar 21 & 6.817502 & 0.046304 & $* * *$ & 91369.97 & $62.16 \%$ \\
\hline Apr 21 & 7.074851 & 0.046541 & $* * *$ & 118186.74 & $29.35 \%$ \\
\hline May 21 & 7.385396 & 0.047584 & $* * *$ & 161226.61 & $36.42 \%$ \\
\hline
\end{tabular}

\section{Most Valuable CryptoPunks}

The most valuable CryptoPunks are displayed in Table 7. The CryptoPunk type "Ape," the CryptoPunk with seven attributes, and CryptoPunks with "Earrings" are excluded since the coefficient and therefore price impact could not be calculated. "Male" CryptoPunks with the "Beanie" attribute are the most valuable ones based on the calculation of $M V P_{c}$. Similarly, "Female" and "Male" CryptoPunks with zero attributes are highly valuable. All CryptoPunk types with the attribute "Beanie" belong to the top 20 most expensive CryptoPunks. Lastly, the CryptoPunk type "Alien", regardless of attribute numbers and attributes, has a high value.

In contrast to that, the least expensive CryptoPunks are "Male" and "Female" assets with the two attributes "Stringy Hair" and "Mole." Interestingly, only 8 out of the 20 have been sold in the observed time period. The CryptoPunks that have not been sold are CryptoPunk numbers 1903, 641, 1050, $2204,281,741,5822,635,5905$, and 198. If an investor could buy one of the CryptoPunks that have not been sold during 
the past three years at a low price point, the resale could have been highly profitable.

Table 7: Most Valuable CryptoPunks

\begin{tabular}{|c|c|c|c|c|}
\hline ID & $\begin{array}{c}\text { CryptoPunk } \\
\text { Type }\end{array}$ & $\begin{array}{c}\text { No. of } \\
\text { Attributes }\end{array}$ & Attributes & $\begin{array}{c}\text { Total Price } \\
\text { Impact } \\
M V P_{c}\end{array}$ \\
\hline 344 & Male & 1 & Beanie & 4.878228572 \\
\hline 1903 & Male & 1 & Beanie & 4.878228572 \\
\hline 2964 & Male & 1 & Beanie & 4.878228572 \\
\hline 641 & Female & 0 & & 2.336907762 \\
\hline 1050 & Female & 0 & & 2.336907762 \\
\hline 2204 & Female & 0 & & 2.336907762 \\
\hline 6487 & Female & 0 & & 2.336907762 \\
\hline 281 & Male & 0 & & 2.333810974 \\
\hline 510 & Male & 0 & & 2.333810974 \\
\hline 741 & Male & 0 & & 2.333810974 \\
\hline 3307 & Male & 0 & & 2.333810974 \\
\hline 2890 & Alien & 1 & Cap & 2.27181816 \\
\hline 7804 & Alien & 3 & $\begin{array}{l}\text { Cap Forward, } \\
\text { Pipe, Small } \\
\text { Shades }\end{array}$ & 2.23834525 \\
\hline 3100 & Alien & 1 & Headband & 2.18559856 \\
\hline 5822 & Alien & 1 & Bandana & 2.18157857 \\
\hline 635 & Alien & 2 & $\begin{array}{l}\text { Bandana, } \\
\text { Regular Shades }\end{array}$ & 2.1477073 \\
\hline 5905 & Alien & 2 & $\begin{array}{l}\text { Do-rag, Small } \\
\text { Shades }\end{array}$ & 2.14436344 \\
\hline 7846 & Male & 2 & $\begin{array}{l}\text { Beanie, 3D } \\
\text { Glasses }\end{array}$ & 1.8608115 \\
\hline 89 & Female & 1 & Choker & 1.74099552 \\
\hline 198 & Male & 2 & $\begin{array}{l}\text { Beanie, } \\
\text { Luxurious } \\
\text { Beard }\end{array}$ & 1.56137627 \\
\hline
\end{tabular}

Figure 4 shows eight of the 20 most valuable CryptoPunks and makes clear that the visual appearance of the CryptoPunks are quite distinct. It can be observed that the "Male" and "Alien" types predominate.

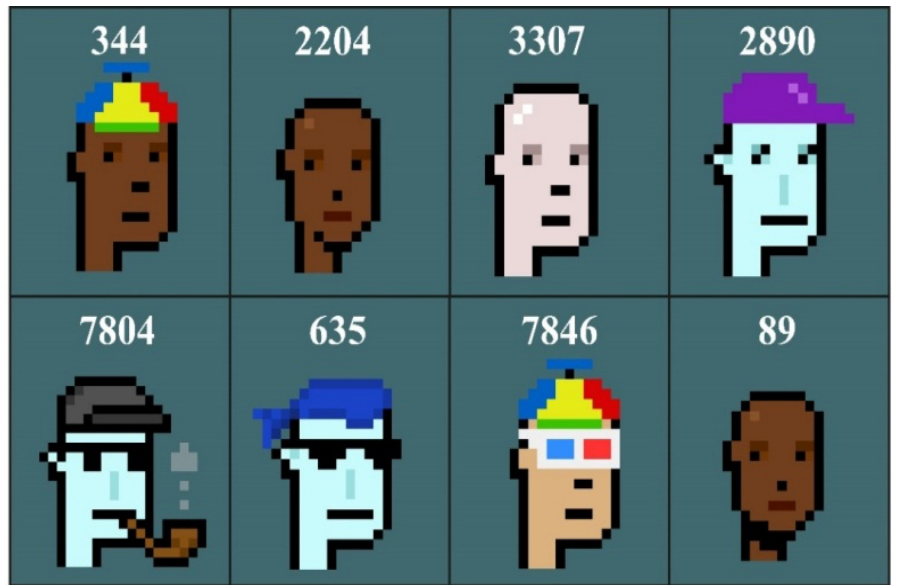

Figure 4: A Sample of Some of the Top 20 Most Valuable CryptoPunks [17]

\section{Comparison to Other Assets}

In order to compare the investment performance of CryptoPunks with other assets, four different time frames are observed: the overall three-year time frame plus breakdowns into Years One, Two, and Three (see Table 8). Over the complete time frame, the CryptoPunk index outperforms all other assets. The CryptoPunk index has appreciated on average $34.19 \%$ each month over the three years observed. Besides that, the Sharpe ratio is the highest among all assets at 0.5338. This shows that even though the standard deviation is very high with a rate of more than $60 \%$, this would still be the best investment to choose according to the risk-adjusted return. Over the same time period, the cryptocurrencies Bitcoin and Ethereum are shown outperforming the more traditional assets but still not performing as well as CryptoPunks.

The yearly performance of the CryptoPunk index also demonstrates that it outperforms all other assets. In Year Three CryptoPunks showed the best performance with an average monthly return of $72.92 \%$ and an SR of 0.9230 . This is the best return performance among all years and assets. Bitcoin and Ethereum did not match this performance, but gave better returns than the other assets in Years One and Two. Similar to CryptoPunks, their performance significantly increased in Year Three. Ethereum's performance in Year Three shows an average monthly return rate of $27.55 \%$ and an SR of 0.9262 close to CryptoPunks' performance. In comparison to the results from other research within the art and collectibles market, the return rates of CryptoPunks are also favourable. In previous studies, the art market has shown annual returns of between $3.97 \%$ and $40 \%$ with high standard deviations depending on the geographical location $[19,15]$. The collectibles market, meanwhile, has shown annual returns of between $-8,7 \%$ and 25.67 [11]. However, it is important to keep in mind that the "return" does not include transaction costs involved in the buying of NFTs. The fees incurred when buying an NFT, referred to as "gas fees," and the fees when you buy Ethereum cannot be underestimated.

If one is only considering its ROI, the NFT market seems more appealing than any comparable investment. But when analysed in the light of the standard deviation it becomes clear that this market is also highly volatile. Even though its SR shows a good return-risk trade-off, the risks inherent in a new irrational and highly volatile market cannot be underestimated. If one is looking to decide whether to invest in physical or digital heterogeneous goods, the results of this paper suggest that NFTs can be a better investment in comparison to, for example, investments in the physical art market. While both are risky investments, the risk-return trade-off is much better for the NFT market. Despite its return rates currently being higher, the market is also more accessible and transparent; and transactions can be effected much quicker. Also, investors do not need to worry about the oncosts of storage space and transportation since everything is digital. Obviously, this statement assumes that the historical patterns observed during this research will continue to hold in the future, something which cannot be guaranteed. 
Table 8: Comparison of Investment Performance

\begin{tabular}{|c|c|c|c|c|c|c|c|c|}
\hline & CryptoPunks & T-Bill & $\begin{array}{l}\text { 10-Year US } \\
\text { Bond }\end{array}$ & World Equity & US Equity & Bitcoin & Ethereum & $\begin{array}{l}\text { US Real Estate } \\
\text { REIT }\end{array}$ \\
\hline \multicolumn{9}{|c|}{ All-Time $(06 / 2018-05 / 2021)$} \\
\hline $\begin{array}{l}\text { Monthly Return } \\
\text { Mean }\end{array}$ & $34.19 \%$ & $1.22 \%$ & $-0.40 \%$ & $1.16 \%$ & $1.45 \%$ & $7.61 \%$ & $9.40 \%$ & $1.02 \%$ \\
\hline $\begin{array}{l}\text { Standard } \\
\text { Deviation }\end{array}$ & $61.76 \%$ & $1.00 \%$ & $15.54 \%$ & $5.27 \%$ & $5.45 \%$ & $22.80 \%$ & $30.22 \%$ & $5.48 \%$ \\
\hline Sharpe Ratio & 0.5338 & & -0.1041 & -0.0113 & 0.0428 & 0.2806 & 0.2709 & -0.0361 \\
\hline \multicolumn{9}{|c|}{ Year $1(06 / 2018-05 / 2019)$} \\
\hline $\begin{array}{l}\text { Monthly Return } \\
\text { Mean }\end{array}$ & $8.93 \%$ & $2.25 \%$ & $-2.38 \%$ & $-0.08 \%$ & $0.24 \%$ & $5.37 \%$ & $-0.54 \%$ & $1.05 \%$ \\
\hline $\begin{array}{l}\text { Standard } \\
\text { Deviation }\end{array}$ & $21.76 \%$ & $0.20 \%$ & $6.95 \%$ & $4.69 \%$ & $5.16 \%$ & $24.24 \%$ & $29.29 \%$ & $4.64 \%$ \\
\hline Sharpe Ratio & 0.3070 & & -0.6661 & -0.4960 & -0.3897 & 0.1288 & -0.0954 & -0.2597 \\
\hline \multicolumn{9}{|c|}{ Year $2(06 / 2019-05 / 2020)$} \\
\hline $\begin{array}{l}\text { Monthly Return } \\
\text { Mean }\end{array}$ & $18.61 \%$ & $1.41 \%$ & $-7.88 \%$ & $0.60 \%$ & $1.10 \%$ & $2.49 \%$ & $2.15 \%$ & $-0.54 \%$ \\
\hline $\begin{array}{l}\text { Standard } \\
\text { Deviation }\end{array}$ & $46.20 \%$ & $0.74 \%$ & $15.70 \%$ & $6.20 \%$ & $6.42 \%$ & $18.70 \%$ & $26.38 \%$ & $7.03 \%$ \\
\hline Sharpe Ratio & 0.3721 & & -0.5920 & -0.1309 & -0.0487 & 0.0576 & 0.0278 & -0.2781 \\
\hline \multicolumn{9}{|c|}{ Year $3(06 / 2020-05 / 2021)$} \\
\hline $\begin{array}{l}\text { Monthly Return } \\
\text { Mean }\end{array}$ & $72.92 \%$ & $0.07 \%$ & $8.89 \%$ & $2.84 \%$ & $2.90 \%$ & $14.79 \%$ & $25.77 \%$ & $2.55 \%$ \\
\hline $\begin{array}{l}\text { Standard } \\
\text { Deviation }\end{array}$ & $78.93 \%$ & $0.04 \%$ & $16.37 \%$ & $4.21 \%$ & $4.16 \%$ & $23.35 \%$ & $27.75 \%$ & $3.70 \%$ \\
\hline Sharpe Ratio & 0.9230 & & 0.5388 & 0.6576 & 0.6819 & 0.6304 & 0.9262 & 0.6707 \\
\hline
\end{tabular}

Table 9 displays the correlation matrix of returns of all assets. The correlation between CryptoPunks and the TBill, the 10-year US Bond, Bitcoin and Ethereum are \pm 0.25 or higher, which indicates some co-movements between those markets. This supports Dowling's (2021b) findings that suggest that NFTs are a low-correlation asset class that show some co-movement with different cryptocurrencies. It is noteworthy that the T-Bill and CryptoPunks have a negative correlation of -0.44 . Therefore, the low T-Bill interest rates seem to encourage investors to look for assets such as NFTs in the form of CryptoPunks. Furthermore, the correlation between both cryptocurrencies can be explained by the dependency of NFTs on cryptocurrencies. The correlation with Bitcoin is higher than with Ethereum which might provide an area for further research since CryptoPunks are paid with Ethereum. Generally, the results suggest that CryptoPunks are suitable for use in portfolio diversification.

Table 9: Correlation of Returns

\section{Conclusion}

The rapid growth of the NFT market is seen as a new opportunity by many investors, but the economics of NFTs are not well yet understood, due to the novelty of the field. It is important, therefore, to measure the financial performance of this new asset class. In order to do so, this paper used hedonic regression (HR) to investigate the NFT collection named CryptoPunks using a data set of more than 11,000 transactions. More specifically, this paper focused on evaluating the investment performance, assessing the variables that determine prices within the CryptoPunks collection, investigating its portfolio diversification potential, and comparing the investment performance to other financial assets. The hedonic index indicates that the CryptoPunk prices have on average increased monthly by $34.19 \%$ with a standard deviation of $61.76 \%$ over the past three years. This return rate is higher than any other investment type that formed part of this paper's research. Next to that, the Sharpe ratio (SR) indicates a good return-risk trade-off. One main finding based

\begin{tabular}{|l|c|c|c|c|c|c|c|c|}
\hline & $\begin{array}{c}\text { Crypto- } \\
\text { Punks }\end{array}$ & T-Bill & $\begin{array}{c}\text { 10-Year US } \\
\text { Bond }\end{array}$ & World Equity & US Equity & Bitcoin & $\begin{array}{c}\text { Ethereum } \\
\text { US Real Estate } \\
\text { REIT }\end{array}$ \\
\hline CryptoPunks & 1.00 & & & & & & & \\
\hline T-Bill & $-\mathbf{0 . 4 4}$ & 1.00 & & & & & & \\
\hline $\begin{array}{l}\text { 10-Year US } \\
\text { Bond }\end{array}$ & $\mathbf{0 . 3 6}$ & $-\mathbf{0 . 2 7}$ & 1.00 & & & & \\
\hline World Equity & 0.04 & -0.21 & $\mathbf{0 . 4 0}$ & 1.00 & & & & \\
\hline US Equity & 0.02 & -0.21 & $\mathbf{0 . 3 8}$ & $\mathbf{0 . 9 9}$ & 1.00 & & & \\
\hline Bitcoin & $\mathbf{0 . 3 6}$ & -0.18 & 0.22 & $\mathbf{0 . 3 2}$ & $\mathbf{0 . 3 1}$ & 1.00 & & \\
\hline Ethereum & $\mathbf{0 . 2 6}$ & $\mathbf{- 0 . 3 7}$ & 0.12 & $\mathbf{0 . 2 9}$ & $\mathbf{0 . 2 6}$ & $\mathbf{0 . 6 9}$ & 1.00 & \\
\hline $\begin{array}{l}\text { US Real Estate } \\
\text { REIT }\end{array}$ & 0.13 & -0.06 & $\mathbf{0 . 3 0}$ & $\mathbf{0 . 8 3}$ & $\mathbf{0 . 8 2}$ & $\mathbf{0 . 3 1}$ & $\mathbf{0 . 3 0}$ & \\
\hline
\end{tabular}


on the HR analysis is that the rarity of the attributes of the CryptoPunks has a positive effect on prices. This is consistent with research findings in the physical collectibles market. Moreover, CryptoPunks is a suitable investment for diversification since the correlation with other assets is relatively low.

Another major factor for consideration when deciding to invest in a new asset is whether it has the potential to grow. This seems to be the case for NFTs given that there are application cases specifically in the gaming, sport, and art industries. Next to that, once major challenges like usability and the lack of a legal form of ownership of NFTs are overcome, the market will reach a broader audience and thus the market will grow still further. However, despite the many positive aspects to NFT collectible investment, the high volatility, illiquidity, and irrationality of this market cannot be underestimated.

This paper aims to provide the first exploration of NFTs from an economic perspective. Its results suggest that, in comparison to other studies that have investigated the art market as providing alternative assets, the NFT market has the potential to offer a more profitable ROI. Its findings also accord with previous studies that investigated the impact of the rarity of a collectible on its value.

The main limitations of this paper are the small data set and the relatively short time period that is observed. In order to achieve a more precise overview of the entire NFT market, it is important to keep exploring this new asset class. Nothing in this paper can be considered to be financial advice.

\section{Competing Interests:}

None declared.

Ethical Approval:

Not applicable.

\section{Author's Contribution:}

Not applicable.

Funding:

This research was self-funded.

Acknowledgements:

Not applicable.

\section{References:}

[1] D. Kelly and G. Zuppinger, "Non-Fungible Tokens Quarterly Report," Q1, 2021. Available: https://nonfungible.com/subscribe/nft-report-q1-2021

[2] NonFungible, 2021, Market Overview, [Online]. Available: https://nonfungible.com/market/history

[3] DappRadar, 2021, NFTs Overview: Discover the hottest NFT collections, marketplace rankings, and top real-time sales [Online]. Available: https://dappradar.com/nft
[4] M. Dowling, "Fertile LAND: Pricing non-fungible tokens," 2021, Finance Research Letters: 102096

[5] M. Dowling, "Is non-fungible token pricing driven by cryptocurrencies?," 2021, Finance Research Letters: 102097

[6] L. Ante, "The non-fungible token (NFT) market and its relationship with Bitcoin and Ethereum," Blockchain Research Labs, 2021.Available: http://dx.doi.org/10.2139/ssrn.3861106

[7] R. Mamarbachi, M. Day, and G. Favato, "Art as an Alternative Investment Asset.” Journal of Financial Transformation. vol. 24, issue 1, pp. 63-71, 2008.

[8] V. Ginsburgh, J. Mei and M. Moses, "The Computation of Prices Indices," in Handbook of the Economics of Art and Culture, V. Ginsburgh, Ed. Amsterdam, Philadelphia: Elsevier, 2006, pp. 947-979.

[9] M. Bailey, R. Muth and H. Nourse, "A Regression Method for Real Estate Price Index Construction." Journal of the American Statistical Association. vol. 58, issue 304, pp. 933942, 1963.

[10] S. Rosen, "Hedonic Prices and Implicit Markets: Product Differentiation in Pure Competition," Journal of Political Economy, vol. 82, issue 1, pp. 34-55, 1974.

[11] B.J. Burton and J.P. Jacobsen "Measuring Returns on Investments in Collectibles," Journal of Economic Perspectives, vol. 13, issue 4, pp. 193-212, 1999.

[12] K. Koford and A.E. Tschoegl, (1998) "The Market Value of Rarity," Journal of Economic Behavior \& Organization, vol. 34, issue 3, pp. 445-457, 1998.

[13] J. Hughes, "Demand for Rarity: Evidence from a Collectible Good," Journal of Industrial Economics, 2020.

[14] A.C. Worthington and H. Higgs, "Art As an Investment: Risk, Return and Portfolio Diversification in Major Painting Markets," Accounting and Finance, vol. 44, issue 2, pp. 257-271, 2004.

[15] L. Renneboog and C. Spaenjers, "Buying Beauty: On Prices and Returns in the Art Market," Management Science, vol. 59, issue 1, pp. 36-53, 2013.

[16] A. Zhukova, V. Lakshina and L. Leonova, "Hedonic Pricing on the Fine Art Market," Information, vol. 11, issue 5, p. 252, 2020.

[17] Larva Labs, 2021, CryptoPunks, [Online.] Available: https://www.larvalabs.com/cryptopunks

[18] A. Kalyvas, P. Papakyriakou, A. Sakkas, et al., "What Drives Bitcoin's Price Crash Risk?,” Economics Letters, 191: 108777, 2020.

[19] R. Kraeussl and R. Logher, "Emerging Art Markets," Emerging Markets Review, vol. 11, issue 4, pp. 301-318, 2010. 


\section{Appendices}

Appendix 1 - CryptoPunk Attributes and Their Prevalence

Table 10: Prevalence of CryptoPunk Attributes

\begin{tabular}{|c|c|c|}
\hline \multirow{2}{*}{ Attribute } & \multicolumn{2}{|c|}{ Prevalence } \\
\hline & Total & $\%$ \\
\hline Beanie & 44 & 0.44 \\
\hline Choker & 48 & 0.48 \\
\hline Pilot Helmet & 54 & 0.54 \\
\hline Tiara & 55 & 0.55 \\
\hline Orange Side & 68 & 0.68 \\
\hline Buck Teeth & 78 & 0.78 \\
\hline Welding Goggles & 86 & 0.86 \\
\hline Pigtails & 94 & 0.94 \\
\hline Pink with Hat & 95 & 0.95 \\
\hline Top Hat & 115 & 1.15 \\
\hline Spots & 124 & 1.24 \\
\hline Rosy Cheeks & 128 & 1.28 \\
\hline Blonde Short & 129 & 1.29 \\
\hline Wild White Hair & 136 & 1.36 \\
\hline Cowboy Hat & 142 & 1.42 \\
\hline Wild Blonde & 144 & 1.44 \\
\hline Straight Hair Blonde & 144 & 1.44 \\
\hline Big Beard & 146 & 1.46 \\
\hline Half Shaved & 147 & 1.47 \\
\hline Vampire Hair & 147 & 1.47 \\
\hline Red Mohawk & 147 & 1.47 \\
\hline Blonde Bob & 147 & 1.47 \\
\hline Clown Hair Green & 148 & 1.48 \\
\hline Straight Hair Dark & 148 & 1.48 \\
\hline Straight Hair & 151 & 1.51 \\
\hline Silver Chain & 156 & 1.56 \\
\hline Dark Hair & 157 & 1.57 \\
\hline Purple Hair & 165 & 1.65 \\
\hline Gold Chain & 169 & 1.69 \\
\hline Medical Mask & 175 & 1.75 \\
\hline Tassle Hat & 178 & 1.78 \\
\hline Fedora & 186 & 1.86 \\
\hline Police Cap & 203 & 2.03 \\
\hline Clown Nose & 212 & 2.12 \\
\hline Smile & 238 & 2.38 \\
\hline Cap Forward & 254 & 2.54 \\
\hline Hoodie & 259 & 2.59 \\
\hline Front Beard Dark & 260 & 2.60 \\
\hline Frown & 261 & 2.61 \\
\hline Purple Eye Shadow & 262 & 2.62 \\
\hline Handlebars & 263 & 2.63 \\
\hline Blue Eye Shadow & 266 & 2.66 \\
\hline Green Eye Shadow & 271 & 2.71 \\
\hline Vape & 272 & 2.72 \\
\hline Front Beard & 273 & 2.73 \\
\hline Chinstrap & 282 & 2.82 \\
\hline 3D Glasses & 286 & 2.86 \\
\hline Luxurious Beard & 286 & 2.86 \\
\hline Moustache & 288 & 2.88 \\
\hline Normal Beard Black & 289 & 2.89 \\
\hline Normal Beard & 292 & 2.92 \\
\hline Eye Mask & 293 & 2.93 \\
\hline Goat & 295 & 2.95 \\
\hline Shaved Head & 300 & 3.00 \\
\hline
\end{tabular}

\begin{tabular}{|l|c|c|}
\hline \multirow{2}{*}{\multicolumn{1}{|c|}{ Attribute }} & \multicolumn{2}{|c|}{ Prevalence } \\
\cline { 2 - 3 } & Total & $\%$ \\
\hline Do-rag & 300 & 3.00 \\
\hline Peak Spike & 303 & 3.03 \\
\hline Mutton Chops & 303 & 3.03 \\
\hline Pipe & 317 & 3.17 \\
\hline VR & 332 & 3.32 \\
\hline Cap & 351 & 3.51 \\
\hline Small Shades & 378 & 3.78 \\
\hline Clown Eyes Green & 382 & 3.82 \\
\hline Clown Eyes Blue & 384 & 3.84 \\
\hline Headband & 406 & 4.06 \\
\hline Crazy Hair & 414 & 4.14 \\
\hline Knitted Cap & 419 & 4.19 \\
\hline Mohawk Dark & 429 & 4.29 \\
\hline Mohawk Thin & 441 & 4.41 \\
\hline Mohawk & 441 & 4.41 \\
\hline Frumpy Hair & 442 & 4.42 \\
\hline Wild Hair & 447 & 4.47 \\
\hline Messy Hair & 460 & 4.60 \\
\hline Eye Patch & 461 & 4.61 \\
\hline Stringy Hair & 463 & 4.63 \\
\hline Bandana & 481 & 4.81 \\
\hline Classic Shades & 502 & 5.02 \\
\hline Shadow Beard & 526 & 5.26 \\
\hline Regular Shades & 527 & 5.27 \\
\hline Big Shades & 535 & 5.35 \\
\hline Horned Rim Glasses & 535 & 5.35 \\
\hline Nerd Glasses & 572 & 5.72 \\
\hline Black Lipstick & 617 & 6.17 \\
\hline Mole & 644 & 6.44 \\
\hline Purple Lipstick & 655 & 6.55 \\
\hline Hot Lipstick & 696 & 6.96 \\
\hline Cigarette & 961 & 9.61 \\
\hline Earring & 2459 & 24.59 \\
\hline
\end{tabular}

Appendix 2 - Goodness-of-Fit Plots

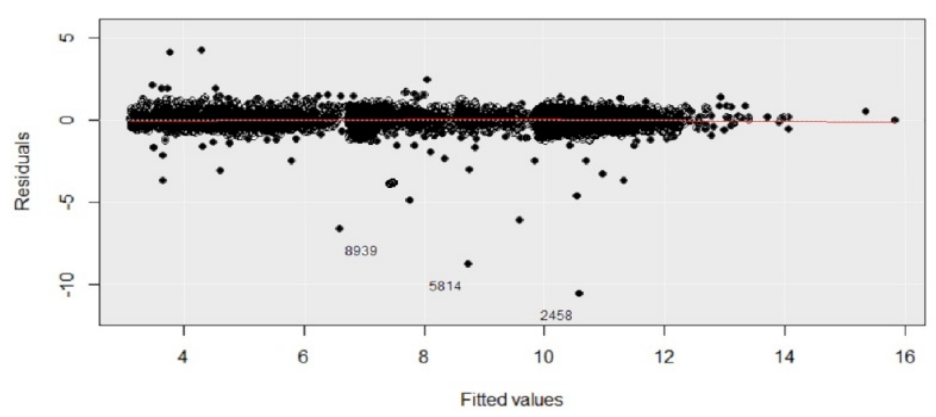

Figure 5: Residuals vs. Fitted Values Plot

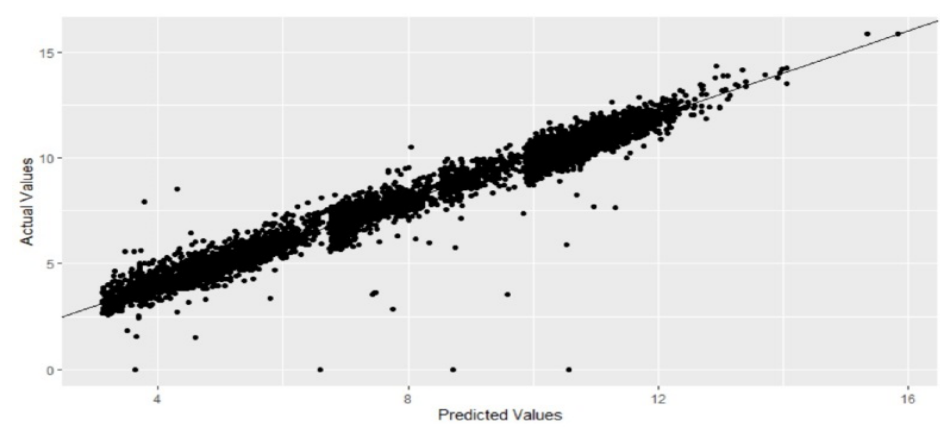

Figure 6: Actual vs. Predicted Values Plot 